\title{
Utilização de produtos naturais da região do Xingu-PA em experimentos didáticos para o ensino de química orgânica
}

\author{
Use of natural products in the Xingu-PA region in educational experiments for organic chemistry \\ teaching \\ J. R. L. Lacerda ${ }^{1}$; R. P. Reis ${ }^{1} ;$ M. A. B. Santos ${ }^{2 *}$ \\ ${ }^{1}$ Curso de Licenciatura em Ciências Naturais, UEPA-Campus IX, 68377-078, Altamira-PA, Brasil \\ ${ }^{2}$ Departamento de Ciências Naturais, Universidade do Estado do Pará, Campus IX, 68377-078, Altamira-PA, Brasil \\ *mbsantos81@gmail.com
}

(Recebido em 18 de abril de 2016; aceito em 02 de maio de 2016)

\begin{abstract}
A experimentação e a contextualização no ensino de Química são aliadas no processo de ensino aprendizagem, por facilitar e motivar os alunos na compreensão dos conteúdos e também por ajudar a desenvolver a capacidade de compreender os fenômenos químicos presente em seu dia-a-dia. $\mathrm{O}$ emprego de aulas práticas experimentais torna-se uma estratégia didática importante para o processo de construção de conhecimento científico estimulando assim o caráter investigativo do aluno, vale ressaltar a importância da teoria com a prática para construção do conhecimento. A pesquisa foi desenvolvida em uma escola pública do município de Altamira - PA com a turma do $3^{\circ}$ ano do ensino médio turno da tarde. A prática foi realizada com a presença de 30 (trinta) alunos e dividida em 03 (três) momentos; aula dialogada e participativa onde foram introduzidos os conceitos facilitadores na aprendizagem de compostos Químicos, uma atividade experimental utilizando materiais de fácil acesso e de baixo custo na construção de um extrator artesanal para a extração de óleo essencial da planta Alfavaca (Ocimum Basilicum L.), e a aplicação de um questionário com o intuito de verificar a aprendizagem por parte dos estudantes. Os resultados permitiram perceber a interferência no ensino formal quando se pretende medi|ar aprendizagens por descoberta e em que medida a experimentação pode tornar a aprendizagem significativa, e aponta que os alunos consideraram importante o uso de aulas experimentais no ensino de química, sendo um momento de complemento à aula teórica e um reforço no aprendizado.
\end{abstract}

Palavras-chave: Ensino de Química Orgânica. Experiência. Óleo Essencial

The Experimentation and contextualization in Chemistry education are combined in the teaching - learning process, making the learning process easier and motivating students understand the contents. It also help to develop the capacity of understand these chemical phenomena in a daily basis. The use of experimental practical classes becomes an important teaching strategy for scientific knowledge-building process, thus stimulating the students' investigative character, it is worth mentioning the importance of theory and practice in the construction of knowledge. The research was conducted in a public school in the city of Altamira - PA. With a senior students group from a high school in the afternoon shift. The practice was carried out in the presence of thirty (30) students and divided into three (03) times; They were dialogic and participatory classes when facilitors concepts were introduced in order to learn the Chemical components. An experimental activity, using easily accessible and inexpensive materials was performed in the construction of a handmade extractor for oil extraction from Basil plant (Ocimum basilicum L.), and the application of a questionnaire in order to check the learning by the students. The results allowed to perceive the interference in the formal education when trying to mediate learning by discovery and to what extent the experimentes can become meaningful learning, and points out that the students considered important to use experimental classes in chemistry teaching, being this a time of complement for theoretical classes and a reinforcement on learning.

Keywords: Organic Chemistr. Teacher training. Essential oil

\section{INTRODUÇÃO}

No ensino das ciências naturais, Biologia, Física, e Química, a experimentação pode ser um aliado estratégico eficiente para demonstrar os conteúdos trabalhados em sala de aula e para a resolução de problemas reais que permitam um ensino aprendizagem significativo. 
A utilização de atividades experimentais no ensino de Química tem sido defendida por vários autores, visto que a prática proporciona a possibilidade de contextualizar o aprendizado. No entanto, é importante valorizarmos a experimentação como forma de relacionar a teoria com a prática no processo de construção do conhecimento, Silva e Zanon [1].

O ensino de Química é muito criticado pelo fato onde o aluno é levado a decorar nomes de fórmulas, compostos, reações e propriedades, sem conseguir relacioná-las cientificamente com a natureza. Na maioria dos casos, o professor não leva em consideração os conhecimentos prévios do aluno que foram construídos ao longo de sua vida.

Para Amaral [2] a disciplina de Química revela a importância de desenvolver atividades experimentais por proporcionar aos estudantes a compreensão científica das informações sobre o tema estudado em sala de aula.

A experimentação é uma metodologia que através das estratégias adotadas podem desperta o interesse e a participação dos alunos. É do conhecimento dos professores de Química que a experimentação em todos os níveis de escolaridade aumenta a capacidade do aprendizado. Chassot [3] enfatiza que a experimentação no âmbito escolar, utilizando experimentos didáticos com os denominados "saberes primevos", desde que se estabeleça um crivo crítico sobre esses saberes é capaz de gerar uma possibilidade de investigação experimental.

Segundo Guimarães [4] a utilização de produtos naturais em atividades experimentais favorece o ensino de Química orgânica. Alves Filho [5] afirma que o uso da experimentação é de suma importância para que as aulas se tornem mais dinâmicas e participativas, constituindo-se deste modo um instrumento eficaz na transmissão do conhecimento como recurso pedagógico capaz de interferir no processo de ensino aprendizagem do aluno.

O tópico química orgânica, alcenos terpenoides faz parte do conteúdo programático das disciplinas de Química ministrado nas escolas do Ensino Médio, os terpenos ligados a outros compostos orgânicos são os principais formadores dos óleos essenciais ou aromáticos. Os óleos essenciais estão presentes em estruturas denominadas tricomas em determinadas partes da planta como: flores, folhas, sementes, entre outros, WolffenbütteL [6]. Todos esses conhecimentos prévios e uma pesquisa bibliográfica foram utilizados para a realização de aula prática experimental, objetivando proporcionar aos alunos uma melhor compreensão das etapas que ocorrem durante um processo da extração na obtenção dos óleos essenciais. A planta utilizada para a realização desta pesquisa foi a alfavaca (Ocimum Basilicum), conhecida na região do Xingu - Pará utilizada pela comunidade local para fins de condimentos e medicamentos.

\subsection{A importância da experimentação}

O presente tema tem por finalidade fazer um discurso sobre a importância das atividades experimentais no ensino de Química, por ser uma disciplina que está relacionada com as necessidades básicas do ser humano. A prática do ensino de Química deve levar o estudante a desenvolver a capacidade de compreender os fenômenos da natureza, cabe ao professor proporcionar metodologias que despertem no educando a curiosidade e o prazer pelo estudo por meio de atividades práticas.

Segundo Queiroz [7] existe um grande desinteresse dos alunos, há falta de espaço adequado nas escolas e laboratórios equipados para realização de aulas práticas. As escolas estaduais do município não oferecem uma estrutura física de qualidade para atender o professor, para que o mesmo possa desenvolver uma aula prática onde através da experiência os alunos possam realizar experimentos no qual possam unir a teoria com a prática em sala de aula, de modo que que a assimilação do conhecimento aconteça de forma significativa por permitir que os alunos relacionem o conteúdo ensinado com a sua realidade. De acordo com Schnetzler [8] as aulas experimentais são relevantes quando apresentam caráter investigativo as ideias podem ser comparadas cientificamente. As experimentações priorizam o contato dos alunos com os fenômenos Químicos, possibilitando assim a criação de modelos que tenham sentindo a partir da observação. 
De acordo com Fonseca [9] a Química não é um objeto, é uma ciência que produz benefício ao homem, cabe ao professor propor atividades práticas e relevantes, de forma a contribuir com o processo de ensino-aprendizagem dos alunos.

As aulas práticas experimentais oferecem um alto nível no desenvolvimento cognitivo do aluno por oferecer possibilidade de explicar as situações do seu cotidiano. O ensino de Química por meio de experimento contribui para a compreensão dos conceitos, os alunos têm a oportunidade de manusearem as substâncias, além de compararem com as atividades teóricas. Para Fonseca [9], os conteúdos de Química não devem serem ensinados desvinculados da prática, no entanto de acordo com Russell [10] as aulas deveriam ser desenvolvidas de modo que seja feita a integração da teoria com a prática e a vivência do aluno.

As atividades experimentais devem proporcionar investigação do tema com base científica, promovendo assim a compreensão dos conceitos científicos confrontando as informações do conhecimento prévio com as novas informações, conforme Demo [11] "o bom professor não é aquele que soluciona os problemas, mas justamente o que ensina os alunos a problematizarem". As aulas experimentais facilitam a aprendizagem dos estudantes, nessas atividades desenvolvidas os alunos aprendem a selecionar as informações e a organizar corretamente os conhecimentos, porque ao manipularem os materiais e ao organizar e praticar a experimentação a aprendizagem concretiza. As aulas experimentais viabilizam a fixação dos conteúdos, daí a importância de as aulas de Químicas serem recomendadas a sua realização por meio de atividades práticas. Para Barberá; Valdés [12] ao priorizar aulas práticas o professor desenvolve nos alunos habilidades necessárias para a solução de problemas. A experiência produz conhecimento, não restringe somente ao saber fazer a prática, mais poderá fazer reflexões sobre o fazer saber, Moraes [13].

A prática do ensino de ciências necessita de uma fundamentação e uma relação entre a teoria e a prática, entre o conhecimento Científico com o senso comum, a disciplina de ciência submetida e articulada a pressupostos teóricos com as estratégias didáticas para a prática do ensino aprendizagem. As atividades experimentais auxiliam os alunos a atingirem níveis de cognição que viabilize a aprendizagem dos conceitos científicos [14].

A utilização da experimentação tem como um dos objetivos o desenvolver do raciocínio lógico dos estudantes [15]. Segundo Schnetzler [8] o professor deve saber identificar o conhecimento prévio que o aluno possui afim de que a atividade proposta seja capaz de envolver os estudantes. Para Brasil [16] no PCNEM o educador encontra metodologias que norteará a experimentação nas aulas de Química de acordo com o contexto do aluno.

De acordo com Ausubel [17] as atividades experimentais viabilizam uma aprendizagem significativa, porque os alunos aprendem a fazer interação dos materiais potencialmente significativos com o conhecimento prévio. $\mathrm{O}$ processo de aprendizagem acontece à medida que $\mathrm{o}$ professor compartilha com os aprendizes.

As aulas realizadas por meio da experimentação estimulam a curiosidade, desafia o cognitivo do aluno, para isso é importante que o professor considere as experiências que os alunos possuem. A realização de experimentos em sala de aula ajuda na interação entre professor e aluno, os estudantes assimilam os conceitos ensinados contribuindo para o desenvolvimento do companheirismo com os colegas, desse modo o educando percebe a construção cientifica do conhecimento ensinado por meio da experimentação.

\subsection{Plantas medicinais e os saberes populares}

A utilização de plantas com fins medicinais era comum na Idade Média, mas os primeiros registros remontam há milênios. Acredita-se que a flora mundial esteja entre 250 mil e 500 mil espécies. O Brasil contribui com 120 mil espécies, a grande maioria na região Amazônica das quais o saber popular selecionou cerca de duas mil como medicinais. Dessas, apenas $10 \%$ foram cientificamente investigadas do ponto de vista Químico - Farmacológico.

Segundo Souza [18], o Brasil possui a mais diversificada flora do mundo e no que concerne as plantas medicinais, estas assumem um papel estratégico, pois segundo a Organização Mundial de Saúde (OMS), $80 \%$ da população mundial depende da medicina tradicional, onde grande parte 
dessa prática envolve o uso de plantas medicinais, utilizando seus extratos vegetais ou seus princípios ativos.

A região Amazônica brasileira é conhecida mundialmente pela sua biodiversidade, sendo estimada em cerca de $20 \%$ do número total de espécies do planeta. A flora, escassa em países desenvolvidos, tem na atualidade valor econômico-estratégico em várias atividades, mas é na área de desenvolvimento de novos medicamentos que reside sua maior potencialidade. Estima-se que $40 \%$ dos medicamentos disponíveis na terapêutica atual foram desenvolvidos de fontes naturais: $25 \%$ de plantas, $13 \%$ de microrganismos e $3 \%$ de animais [19].

De acordo com Firmo et al. [20] planta medicinal é toda planta que administrada ao homem ou animal, por qualquer via ou forma, exerça alguma ação terapêutica. Maciel [21] afirma que o conhecimento popular quando divulga sobre a eficiência de determinada planta medicinal e o seu caráter terapêutico, tornam-se de influência na escolha das espécies para estudos Botânicos, Farmacológicos e Fotoquímicos e auxiliam de forma relevante as pesquisas Científicas.

Accordi et al. [22] em seu levantamento etino botânico em quintais e jardins na zona urbana de Altamira - Pará, observou que as plantas medicinais apresentam maior frequência em relação a árvores frutíferas demonstrando o interesse popular pelas espécies medicinais existindo uma troca de conhecimentos entre vizinhos que mantém o saber popular, sendo que as mulheres mais idosas são as que mais detém esse conhecimento e o valorizam.

As plantas medicinais representam um valioso patrimônio genético natural para países em desenvolvimento como o Brasil, entre essas espécies estão as plantas aromáticas produtoras de óleos essenciais ocupam um lugar de destaque no mercado farmacêutico, perfumaria, cosméticos, e na medicina alternativa [18]. Sendo que seu estudo está direcionado atualmente para espécies que possam produzir fitofármacos de interesse comercial.

Argenta et. al. [23] afirma que o uso de plantas como produtos fitoterápicos constituem-se como único recurso terapêutico em algumas comunidades, sendo esse conhecimento passado de geração a geração e sua utilização no Brasil é tradicional influenciada pelo baixo nível de vida da população e alto custo dos medicamentos.

Chassot [3] alerta sobre o risco do desaparecimento de alguns saberes populares, um valioso aprender na chamada Escola da Vida, quando os detentores destes conhecimentos desaparecem, estes conhecimentos também deixarão de existir, e propõe o resgate destes saberes antes que cause perda ou danos irrecuperáveis, entre eles, os conhecimentos das plantas medicinais e da medicina popular.

\subsection{Alfavaca (Ocimum Basilicum l.)}

Segundo Santos [24] na região do Xingu-PA as folhas da planta Ocimum Basilicum L família lamiace, popularmente conhecida como Alfavaca, é utilizada externamente como cicatrizante (sumo das folhas), ao passo que o banho preparado com as folhas é considerado útil contra dores de cabeça, gripe e catarro no peito, devendo, porém, ser tomado somente à hora que se vai dormir. O decoto das folhas misturado com cravo-da-índia é utilizado externamente contra sinusite, congestão nasal e dor de cabeça, enquanto seu uso interno é indicado contra dores do estômago e de cabeça. As sementes são usadas externamente como antisséptico da região ocular e para eliminar "carne crescida" no olho. As folhas da planta também são usadas como condimento alimentar [25].

Algumas espécies de plantas do gênero Ocimum estão sendo estudadas fitoquímica e farmacologicamente e, com isto, muitos compostos foram isolados e identificados. Assim, diferentes classes de compostos orgânicos de interesse medicinal existentes nessas espécies foram relatadas, incluindo, flavonoides (A) e terpenoides (B), esteroides, triterpenos, taninos e quinonas. 
Tabela 01: Estrutura Química dos componentes da Alfavaca; (A) flavonoides; (B) terpenoides

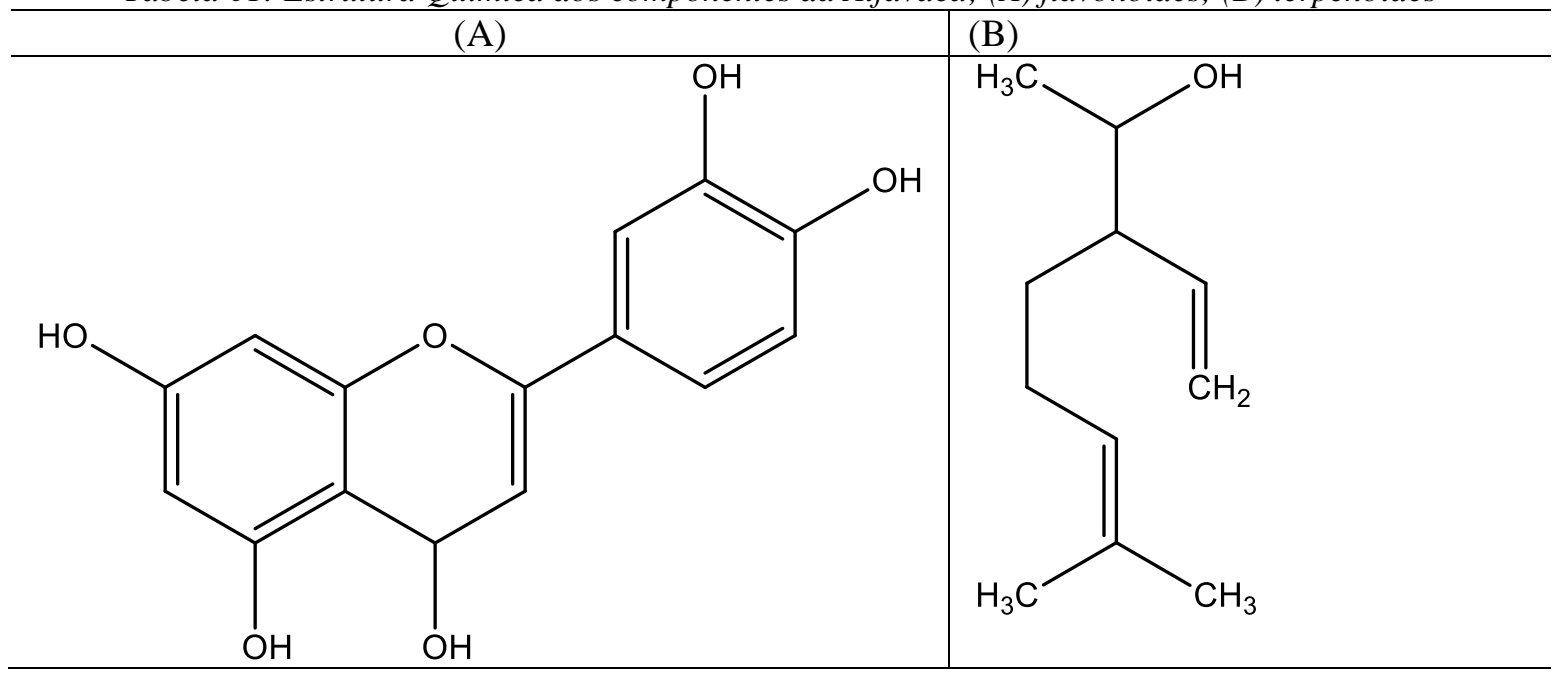

O óleo essencial que pode ser extraído das partes aéreas folhas e flores de Ocimum Basilicum L. (Figura 01) demostrou in vitro atividade antibacteriana contra Staphylococcus aureus, Salmonella enteritidis e Escherichia coli, atividade antisséptica contra Proteus vulgaris, Bacillus substilis e Salmonella paratyph. Siddiqui [26].

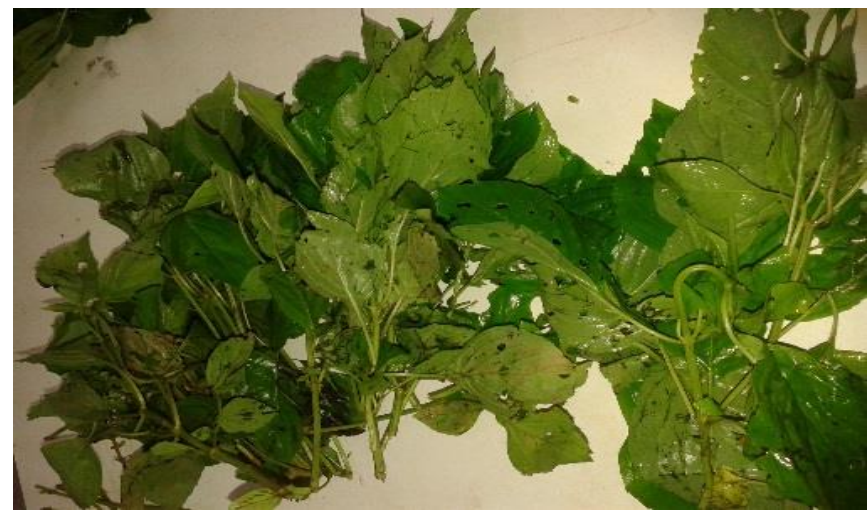

Figura 01: Planta Alfavaca (Ocimum Basilicum L).

Segundo Cechinel; Yunes [27] nos últimos anos os óleos essenciais obtidos de plantas, tem sido considerado fontes em potenciais de substâncias biologicamente ativas. Recentemente estudos de Gorovindarajan et al. [28] comprovaram a ação larvicida sobre mosquitos do gênero Aedes e Anopheles.

A utilização de produtos naturais do Xingu como matéria prima para produção de medicamentos encontra-se relatada em diversos artigos nessa área de pesquisa. Na região do Xingu, Accordi et al. [22] a espécie Ocimum Basilicum L, popularmente conhecida como Alfavaca é comumente encontrada como espécie nativa nos quintais das propriedades rurais e na zona urbana e ribeirinha, seu plantio é feito por pequenos produtores que vendem o produto embalado em pequenos maços na feira do produtor ou supermercados de Altamira. Na Região Norte sua utilização pela população local ocorre na condimentação do tucupi, juntamente com outra erva aromática regional a chicória, componentes de duas iguarias regionais, o pato no tucupi e o tacacá e também no cozimento de peixes.

De acordo com Di Stasi; Hiruma - Lima [25] o gênero Ocimum pertencente a ordem lamiace, é uma das maiores ordens botânicas existentes, apesar de incluir apenas oito famílias, das quais se destacam as Boraginaceae, Verbenaceae e Lamiaceae. Esta última família compreende um grande número de espécies de valor medicinal, espalhadas por todo o planeta. A família Lamiaceae, também denominada Labiatae, foi descrita por Antoine Laurent de Jussieu e inclui cerca de 252 
gêneros, nos quais se distribuem 6.700 espécies, a maioria de arbustos ervas e raramente de árvores, Subfamília Nepetoidea e na região da Mata Atlântica, assim como em todo o Brasil a espécie é chamada de Alfavaca ou Alfavacão. Em outras regiões, de Alfava, Alfavacona, Alfavaquinha, Alfavaca - de - cheiro, Alfavaca - cheirosa, entre outros.

A espécie Ocimum Basilicum L., é uma erva anual, com até $50 \mathrm{~cm}$ de altura ou maior, de caule ramoso, com ramos tetrágonos e pubescentes, de onde partem folhas opostas, ovadas, dentadas, glabras, pequenas e finas; flores brancas ou rosas, aglomeradas no ápice dos ramos e dispostas em espigas. A planta é de origem asiática e muito usada na indústria de perfumaria. O nome do gênero Ocimum, descrito por Carl Linnaeus, significa "perfumada", referindo-se à planta toda.

A identificação da espécie foi obtida através de comparação de registros fotográficos e em livros científicos da área, adotando-se o sistema classificatório APG III (2009), e sua nomenclatura botânica confirmada através da base de dados da Lista das Espécies da Flora do Brasil (http://floradobrasil.jbr.gov.br/2010).

A planta produz óleos essenciais nas seguintes partes: flores, cascas de frutos, folhas e inflorescências. Denomina-se tricomas as "bolsas" onde ficam encapsulados o óleo essencial na planta. Estes tricomas são rompidos naturalmente pela espécie vegetal, liberando o óleo essencial que formam uma espécie de "nuvem aromática" ao seu redor, Wolffenbüttel [4] que atrai insetos polinizadores e repele os insetos causadores de pragas. Os tricomas também são rompidos durante os processos intencionais de extração do óleo essencial.

O óleo essencial não é um produto simples de um componente, é um produto composto, podendo ultrapassar 300 compostos químicos diferentes. Tal diversidade e complexidade fazem do óleo essencial puro um produto altamente valorizado, devido ao seu potencial terapêutico é muito utilizada na área da perfumaria e cosmética devido a sua refinada e complexa composição aromática, área alimentícia devido ao seu potencial como aditivo flavorizante, e na área de aromatização ambiental.

\section{MATERIAL E MÉTODOS}

A pesquisa foi desenvolvida em uma escola pública do município de Altamira - PA, com a turma do $3^{\circ}$ ano do ensino médio turno da tarde, no período de 17/06 a 22/06/2015 como parte da disciplina DCNA - 0996 - Vivências de Química no ensino médio, do curso de Ciências Naturais com habilitação em Química, com carga horária total de 100 horas. A prática foi realizada com a presença de 30 (trinta) alunos.

Em aula dialogada, prática e participativa foram introduzidos os conceitos facilitadores na aprendizagem dos compostos químicos orgânicos conhecidos como óleos essenciais, caracterizando-os como alquenos terpenoides. No decorrer da aula concomitantemente com a explicação os alunos tiveram a oportunidade de manusear através do tato e olfato, diferentes odores e textura presentes em plantas, óleos e perfumes para efeito comparativo.

Para alcançar esse objetivo, utilizou-se a planta Alfavaca (Ocimum Basilicum) da região do Xingu para contextualizar as aulas. Na experiência adicionou-se 200,19 g de folhas e inflorescências de Alfavaca (Ocimum basilicum) em $1.200 \mathrm{~mL}$ de água filtrada no extrator artesanal para o processo de hidro destilação. O experimento consistiu na montagem artesanal de um extrator caseiro, utilizando materiais do cotidiano como garrafa pet, panela de pressão, mini fogão industrial, botijão de gás, mangueiras cristais traçadas, e amianto grafitado.

$O$ problema central deste estudo reside nos desafios que os educadores encontram em utilizarem metodologias que facilitem o processo dos conteúdos de Química nas turmas do ensino médio.

Para Ausubel [29] com base em uma linha cognitivista, a aprendizagem ocorre por meio da agregação dos conteúdos de forma substantiva e não literal na estrutura cognitiva do indivíduo, através da conexão com uma estrutura de conhecimentos específica, chamada de subsunçor, que se refere a uma estrutura cognitiva que funciona como um receptor de novas informações diretamente correlacionada a uma proposição existente, deste modo, experimentação em função do direcionamento a um objeto de pesquisa, teria a função de auxiliar o aluno a evoluir de um 
nível operacional de pensamento para o nível formal, ou seja, a partir de evidências concretas ser capaz de teorizar e construir modelos explicativos ou ir do macroscópico para o microscópico.

As atuais mudanças nos paradigmas no âmbito educacional exigem novas formas de pensar e produzir conhecimentos. O estudo investiga, desta forma o desenvolvimento de práticas no âmbito educacional da rede pública estadual na realização de uma atividade experimental. Para a construção do objeto da pesquisa foi aplicado um questionário semiestruturado com questões abertas e fechadas, o qual permitiu coletar informações sobre o processe de ensino aprendizagem por meio da experimentação. Os dados coletados foram sistematizados de forma descritiva e em gráficos de coluna.

A pesquisa qualitativa não está preocupada com representatividade numérica, mas sim com o aprofundamento da compreensão de um grupo social ou de uma organização. A pesquisa qualitativa se vale das diferentes abordagens e busca explicar o "porque" das coisas, tentando apontar caminhos que devem ser seguidos, mas não quantificar os valores e as trocas simbólicas, nem se propõe a comprovar os fatos, pois os dados analisados podem não ser mensuráveis, ou não se repetirem em outro contexto histórico.

O pesquisador é o principal instrumento na coleta e na análise dos dados "mantendo um esquema flexível que permite rever os pontos críticos da pesquisa, localizar novos sujeitos se necessário incluir novos instrumentos e novas técnicas de coleta de dados, aprofundar certas questões durante o desenrolar do trabalho" [30].

As análises dos dados não ficaram restritas somente em conteúdos, mais em uma experimentação prática, embora tenha sido um instrumento de grande importância para o conhecimento da realidade [31]. A pesquisa deve demonstrar que o pesquisador se esforçou para coletar as evidências, desta forma possibilitou a apreensão da dinâmica das relações que determinou a análise cuidadosa dos dados propostos da pesquisa sobre experimentação no ensino de Química.

\section{RESULTADOS E DISCUSSÃO}

\subsection{Aula introdutória $-1^{\circ}$ Momento}

Ao iniciarmos nossa intervenção pedagógica baseada nos preceitos de aula expositiva dialogada que de acordo com Pina et al. [32] o método expositivo de aula torna-se interessante com a inserção de recursos, de modo que consiga atrair o aluno para o conteúdo, e assim, proporcionar uma aprendizagem satisfatória e pode perfeitamente assumir um caráter transformador por intermédio da troca de experiências entre professor e alunos numa relação dialógica.

Antes de emitir qualquer conceituação sobre plantas medicinais e os demais conceitos Químicos disponibilizamos aos alunos diversas plantas aromáticas regionais, como a erva cidreira (Lippia sp.), alfavaca (Ocimum Basilicum L), o capim santo ou capim limão (Cymbopogon sp), Chicória (Eryngium sp), perfumes e cosméticos (Figura 02.A). Em relação aos produtos apresentados percebemos que os alunos comparavam olfativamente os diferentes odores das plantas e borrifaram perfumes e 08 (oito) deles afirmaram conhecer a planta alfavaca, porém, não souberam explicar sua utilização no cotidiano. Em relação aos óleos, utilizamos uma amostra de óleo essencial e solicitamos aos alunos que verificassem viscosidade, textura em relação ao óleo de amêndoas (Figura 02. B). Após a contextualização socializamos o conceito de plantas medicinais como fornecedoras de compostos químicos para fabricação de cosméticos e medicamentos e que apesar de sua importância o saber popular não é suficiente para validar sua eficácia medicamentosa. Relatamos a importância da experimentação e a validação através da pesquisa científica (Figura 02. C).

Associamos as plantas aromáticas como produtoras de óleos essenciais definidos por estruturas complexas que podem apresentar mais de 100 (cem) compostos químicos, e que apresentam como estrutura base e característica pequenas estruturas alcenicas (Hidrocarbonetos) denominados terpenos, observou-se que os alunos entenderam o conceito sobre plantas 
medicinais aromáticas e não aromáticas e sua utilização sem, contudo, estabelecerem uma ligação com alguns conceitos relacionados ao assunto ministrado.

De acordo com Accordi et al. [22] encontramos uma justificativa para o pouco conhecimento sobre as plantas medicinais por parte dos alunos, que indica a baixa idade no caso das crianças e adolescentes como um dos fatores que influenciam na construção desse conhecimento. Sendo assim esse saber popular encontra-se presente em pessoas mais idosas principalmente mulheres.
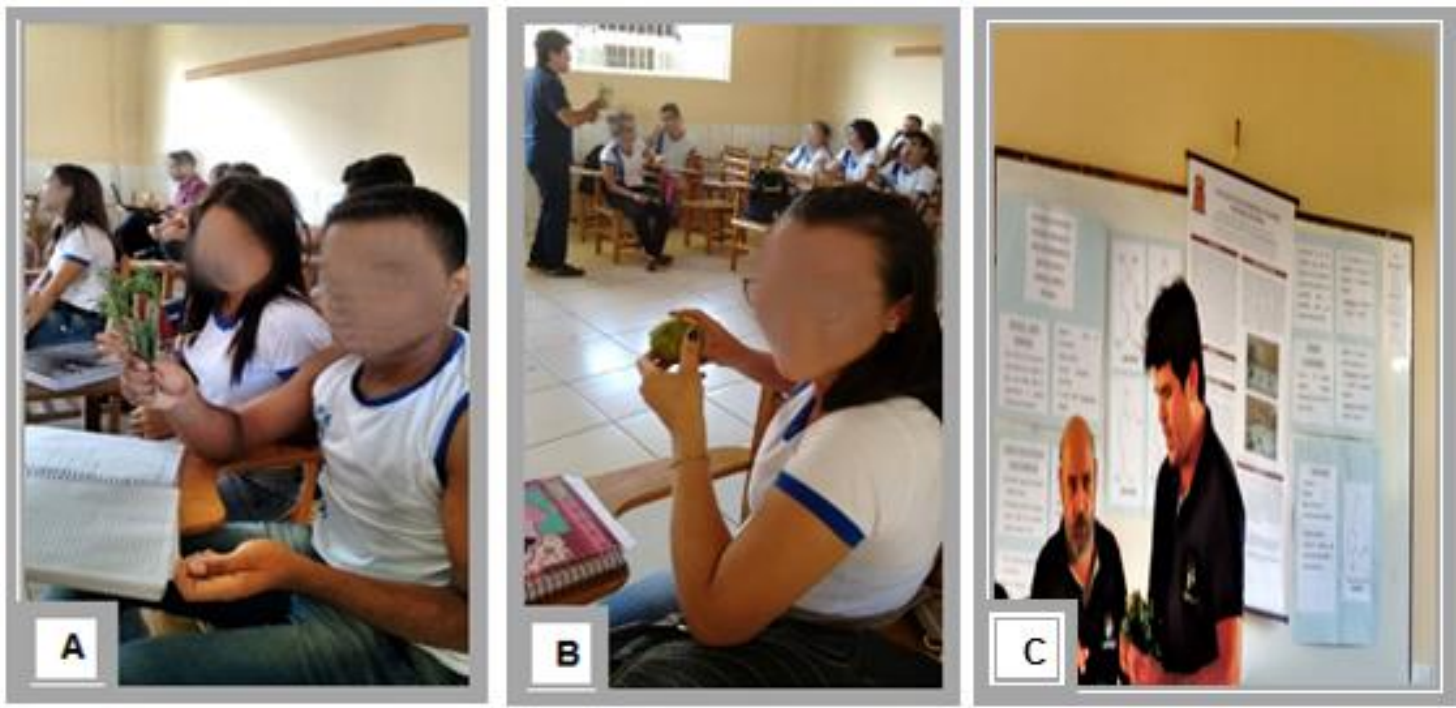

Figura 02: (A) Participação dos alunos na comparação dos produtos apresentados (plantas, perfumes, cosméticos e óleos), (B) diferenciação feita olfativamente. $(\boldsymbol{C})$ Conceito sobre plantas medicinais como fornecedoras de compostos químicos.

\subsection{A experimentação $-2^{\circ}$ Momento}

Nesse momento da intervenção os alunos foram orientados em relação a alguns cuidados a serem tomados durante os processos de destilação a vapor, ouviram atentamente as instruções para a montagem do extrator artesanal. A seguir participaram na retirada de folhas e inflorescências da alfavaca separando-as dos talos e raízes, dois alunos tiveram a curiosidade de questionar a razão de utilizarmos na experiência apenas folhas e inflorescências e não todas as partes da planta (Figura 03.A), explicou-se que em trabalho experimental anterior utilizando método artesanal de hidro destilação foi comprovado maior rendimento de óleo quando foram utilizadas apenas folhas e inflorescências de planta do gênero Ocimum [33].

O material selecionado (Alfavaca) foi colocado em uma panela de pressão e acrescentado $1200 \mathrm{ml}$ de água a qual foi fechada. Em seguida, juntamente com os alunos foi montado parte a parte o extrator artesanal anexando-o em um suporte com garras, sendo que o condensador, feito de uma garrafa pet com água congelada em seu interior recebeu atenção especial, pois os alunos ainda não haviam associado o princípio da liquefação em seu funcionamento, processo que seria somente entendido após a subida do vapor da água pelo tubo plástico (mangueira) e que através do resfriamento o vapor tornava-se líquido. Através da pressão do vapor de água o óleo essencial por sua volatilidade e ponto de fusão menor que o da água foi arrastado depositando-se no frasco coletor (Figura 03. B). A situação criada pelo processo de arraste a vapor otimizou o cheiro do óleo essencial presente na alfavaca que se espalhou por toda sala e os alunos puderam perceber uma nova substância de cor amarelada presente na água no frasco coletor.

Durante a verificação através do teste qualitativo solicitamos aos alunos que por observação tentassem identificar nos dois tubos de ensaio um contendo apenas água e outro tubo contendo a mistura obtida no processo de hidro destilação. No exame comparativo as opiniões se dividiram alguns visualizaram uma turbidez na amostra obtida, outros uma coloração em tons de amarelo, na ocasião explicamos que uma das características das reações Químicas evidencia-se pela mudança de cor durante a reação e que os hidrocarbonetos alcenos em presença de permanganato de potássio $\left(\mathrm{KMnO}_{4}\right)$ reagem e mudam a coloração da solução para o castanho e que através 
dessa reação poderíamos comprovar a presença de grupos alcenos terpênicos na mistura, presentes nos óleos essenciais (Figura 03. C).

Realizou-se a experiência pingando-se algumas gotas nas duas amostras presentes nos tubos de ensaio uma delas contendo somente água conservou a cor lilás da solução de permanganato de potássio $\left(\mathrm{KMnO}_{4}\right)$ um pouco mais clara em função da sua diluição e no tubo contendo a substância obtida pelo processo de arraste a vapor adicionando-se a mesma quantidade de gotas de $\mathrm{KMnO}_{4}$, a coloração mudou para castanho claro evidenciando a presença do óleo essencial (Figura 03. D).
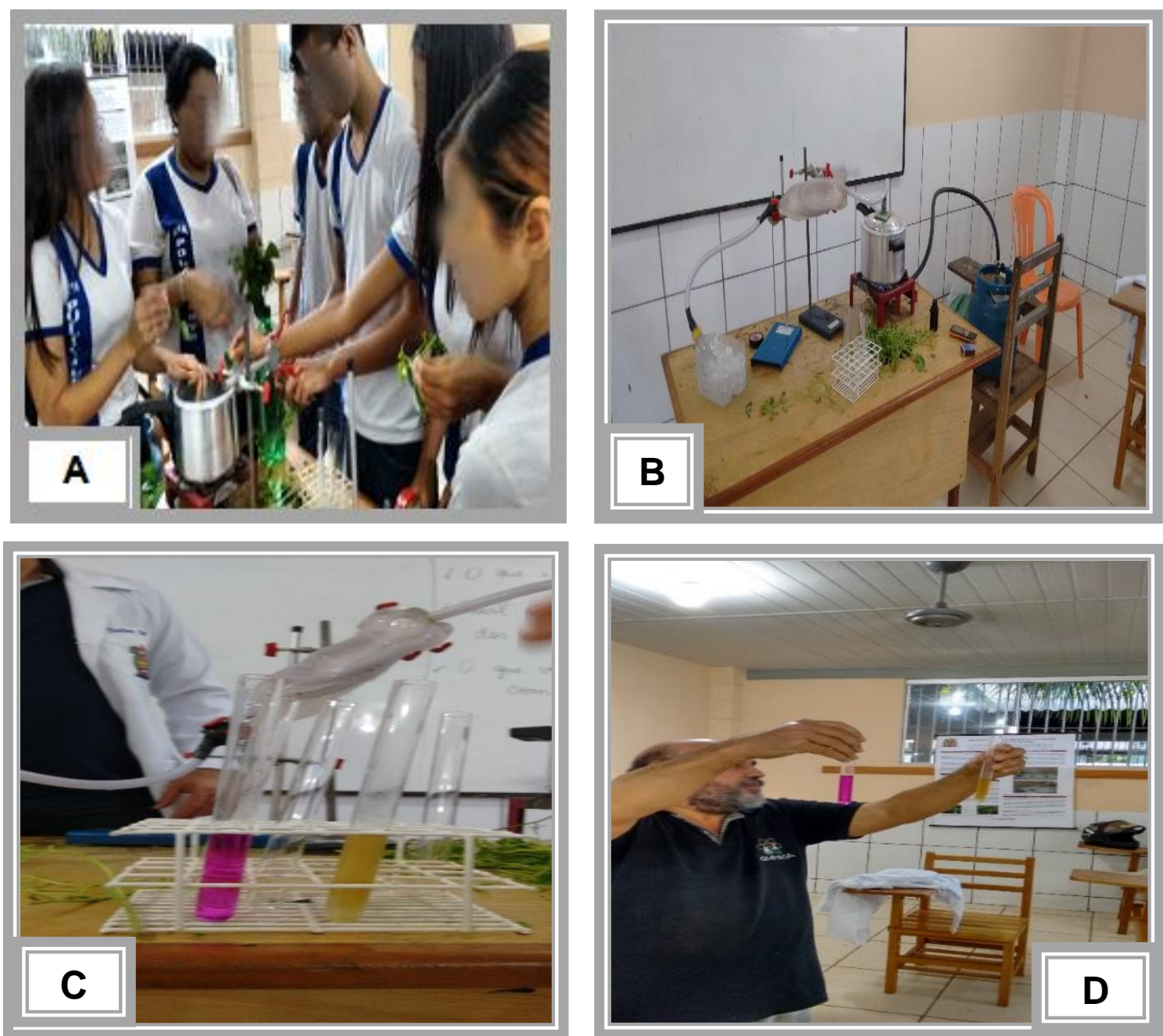

Figura 03: (A) Participação dos alunos na separação das folhas para a realização do experimento. (B) Extrator artesanal de óleos essenciais. (C) Comparação visual das amostras obtidas. (D) Teste qualitativo com uma solução de permanganato de potássio $\left(\mathrm{KMnO}_{4}\right)$

\subsection{Avaliação da aprendizagem $-3^{\circ}$ Momento}

Foi aplicado um questionário contendo 10 (dez) questões, sendo 09 (nove) subjetivas e uma dissertativa com o objetivo de verificar a aprendizagem por parte dos estudantes. O gráfico 1 apresenta a análise das cinco primeiras questões. 
Gráfico 01: Porcentagem de acertos/erros referentes ao questionário avaliativo

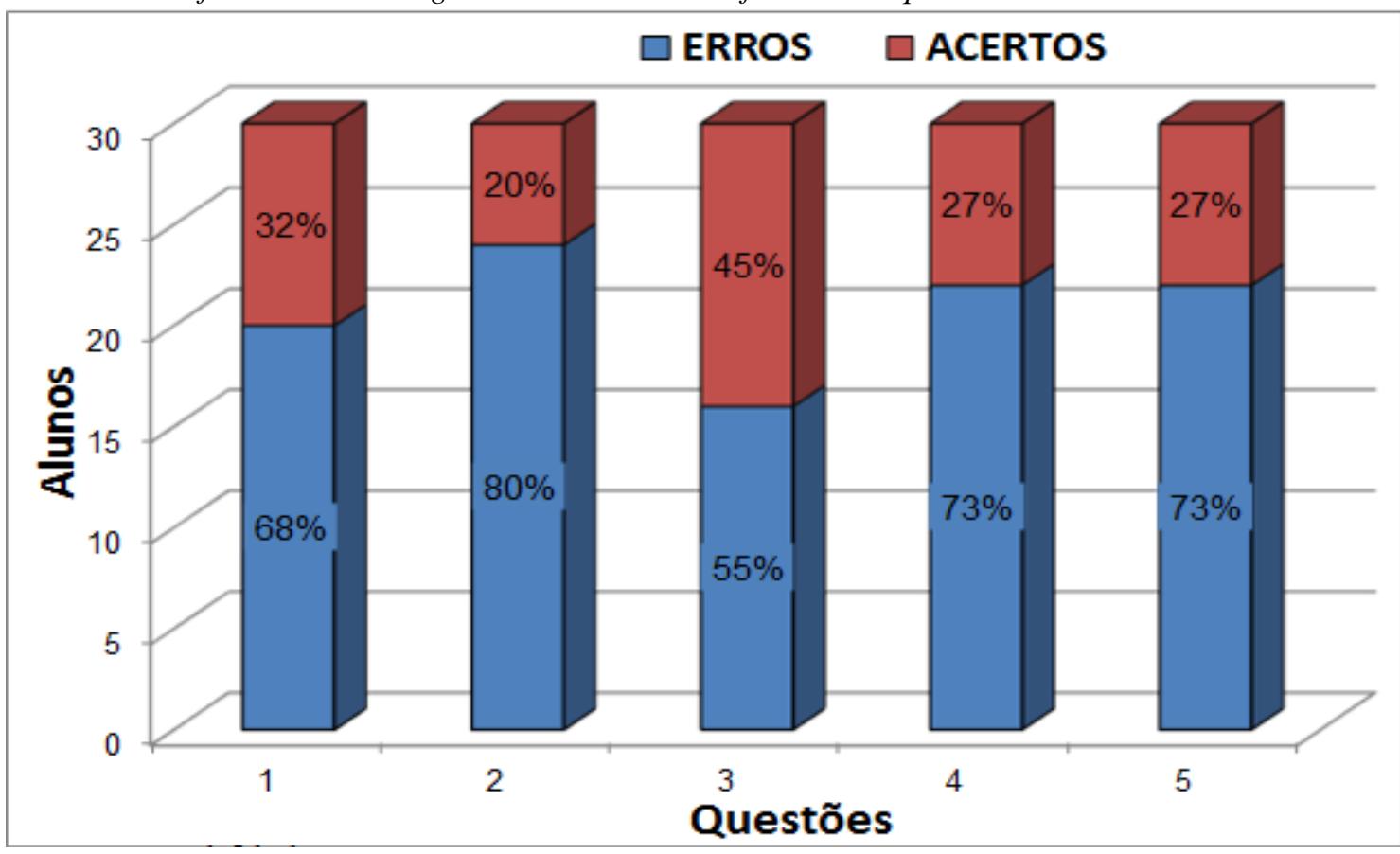

A primeira questão do questionário procurou avaliar o entendimento dos alunos em relação à pesquisa científica e sua utilização nas descobertas científicas. A pesquisa científica nos ajuda a entender o mundo que nos rodeia, tendo como objetivo a solução de problemas de forma racional, analítica, sistemática e metodológica, pois sempre procura meios de provar e questionar teorias.

Apenas 10 (dez) responderam de forma assertiva. Chassot [3] critica o saber que a escola transmite, e que essa ação de transmitir já descaracteriza este saber, pois se estabelece a diferença entre o produzir e transmitir, então como exigir que os alunos entendam de cientificidade, se não lhe proporcionamos alfabetização científica nas escolas.

A questão número 02 (dois), relacionava-se à composição dos óleos essenciais, conceito enfatizado por ocasião da aula expositiva que a função ácidos graxos que não fazia parte da estrutura dos óleos essenciais, os alunos confundiram os nomes funções orgânicas e somente 06 (seis) acertaram. O conteúdo sobre ácidos carboxílicos assim como outras funções oxigenadas ainda não havia sido estudado pelo professor junto aos alunos.

Percebemos neste quesito que para uma melhor avaliação dos alunos seria necessária a utilização de palavras de fácil assimilação, utilizar "gorduras" e não ácidos carboxílicos. De acordo com Braathem [34] para que uma aprendizagem se torne significativa, o aluno precisa possuir um conhecimento específico sobre o assunto para que possa agregar outros novos conhecimentos, considerando-se que esse tipo de aprendizagem não acontece por um processo causa/efeito, onde professor ensina e o aluno aprende.

Na questão de número 03 (três), 14 (quatorze) alunos identificaram os óleos essenciais como um dos compostos não oleosos, isso comprova que o contato com mistura contendo óleo essencial colocado sobre a pele dos alunos foi decisivo na identificação dessa característica. Para Maldaner [35] a importância da experimentação na confirmação de informações conhecidas permite a sua interpretação possibilitando entre outros a elaboração de conceitos. Os alunos ao compararem as texturas da mistura com óleo essencial e o produto comercial óleo de amêndoas perceberam experimentalmente as diferenças quanto a oleosidade.

A quarta questão procurava identificar o elemento Químico presente na formação do óleo essencial, classificando-os em mono, di e tri terpenos. Os alunos não conseguiram atribuir a quantidade do elemento carbono como classificador da função. O resultado nos surpreendeu com o quesito de respostas erradas (vinte e duas), porém, devemos entender a familiarização com a Química inorgânica presente na estrutura cognitiva destes alunos estudada nos últimos dois anos do ensino médio, e o pouco conhecimento de Química Orgânica contribuíram induzidos ao erro 
optando pelo elemento mais conhecidos na Química Inorgânica como o enxofre. Oito alunos acertaram a identificação do elemento Químico presente no óleo essencial. Em nossas aulas de intervenção nunca estabelecemos comentários sobre a presença do elemento químico enxofre na formação do eugenol.

$\mathrm{Na}$ quinta questão o aluno deveria identificar o eugenol e o número de carbonos presentes em sua estrutura. Para avaliar o entendimento dos alunos em relação à quantidade de átomos de carbono terpenoides (mono, di e tri terpenos) somente 08 (oito) alunos responderam corretamente.

Gráfico 02: Porcentagem de acertos/erros referentes às questões de 6 a 9.

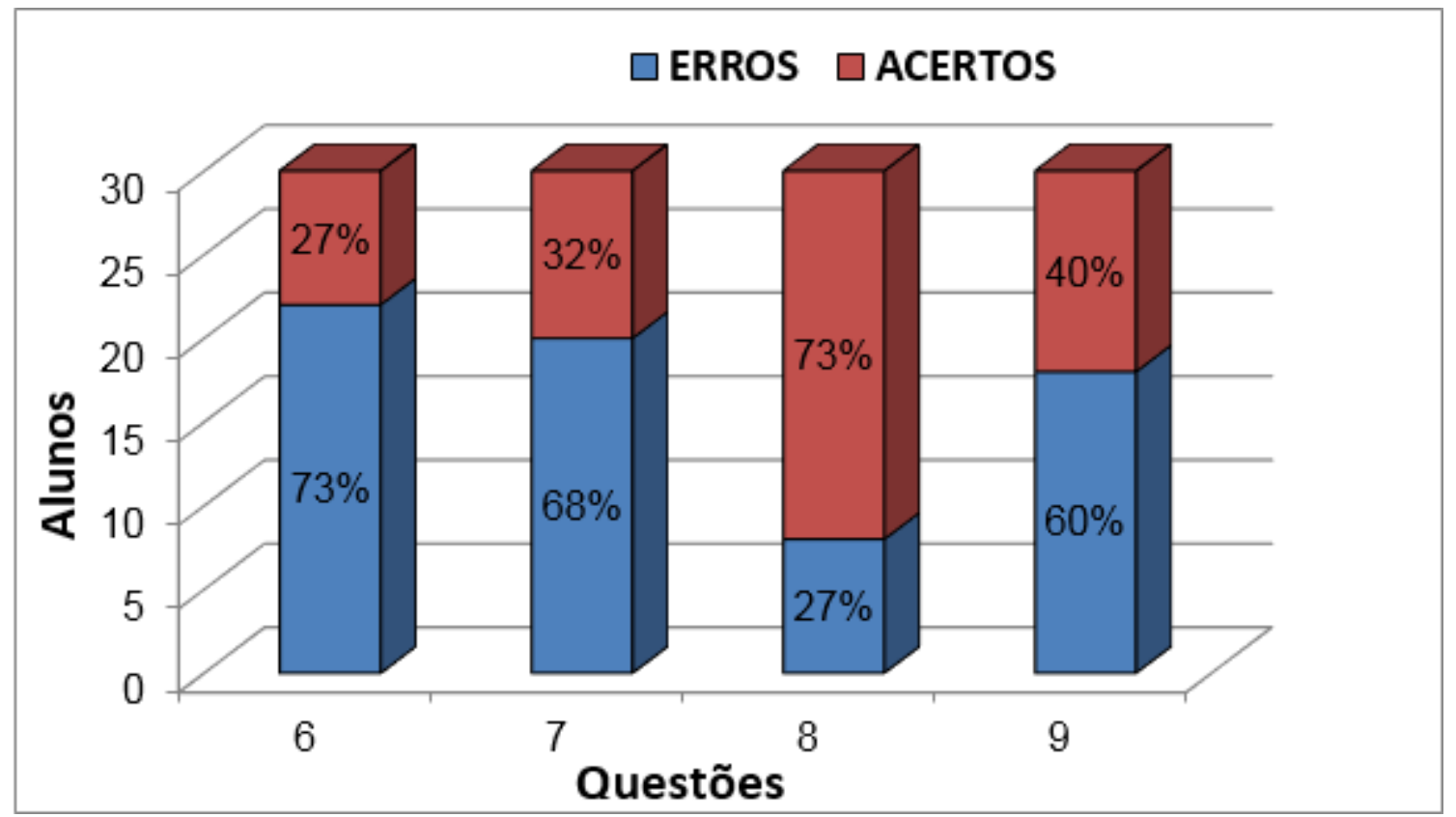

Arquivo Pessoal: Acadêmicos da UEPA.

O gráfico 2 apresenta a analise das questões de 6 a 9. Na sexta questão foi verificado o mesmo número de acertos da questão anterior. Os alunos não conseguiram absorver os conceitos de ponto de ebulição e fusão durante o período em que estudaram estados físicos da matéria, e não conseguiram assimilar os conceitos dados durante a aula experimental, possivelmente por esse motivo não associaram que óleo e água apresentam pontos de ebulição diferentes o que torna possível o processo de destilação.

A questão de número 07 (sete) foi contemplada com 10 (dez) acertos, ela consistia na identificação da fórmula molecular a partir da forma estrutural do eugenol, novamente os conhecimentos básicos sobre compostos orgânicos foram decisivos nos resultados obtidos.

O quesito 08 (oito) apresentou o maior número de respostas certas (vinte e duas), demonstrando que as aulas de práticas experimentais com participação dos alunos criam um clima de descontração, desperta o interesse do aluno independente do seu nível escolar, possibilitando-o a desenvolver competências e habilidades desejáveis, facilitando a aprendizagem, uma vez que, envolve o estudante tornando os conteúdos menos abstratos [36]. Vinte e dois alunos conseguiram relacionar o processo de arraste a vapor com a extração do óleo essencial, conceito que consideramos precursor para agregação de novos conhecimentos (Figura 04). 


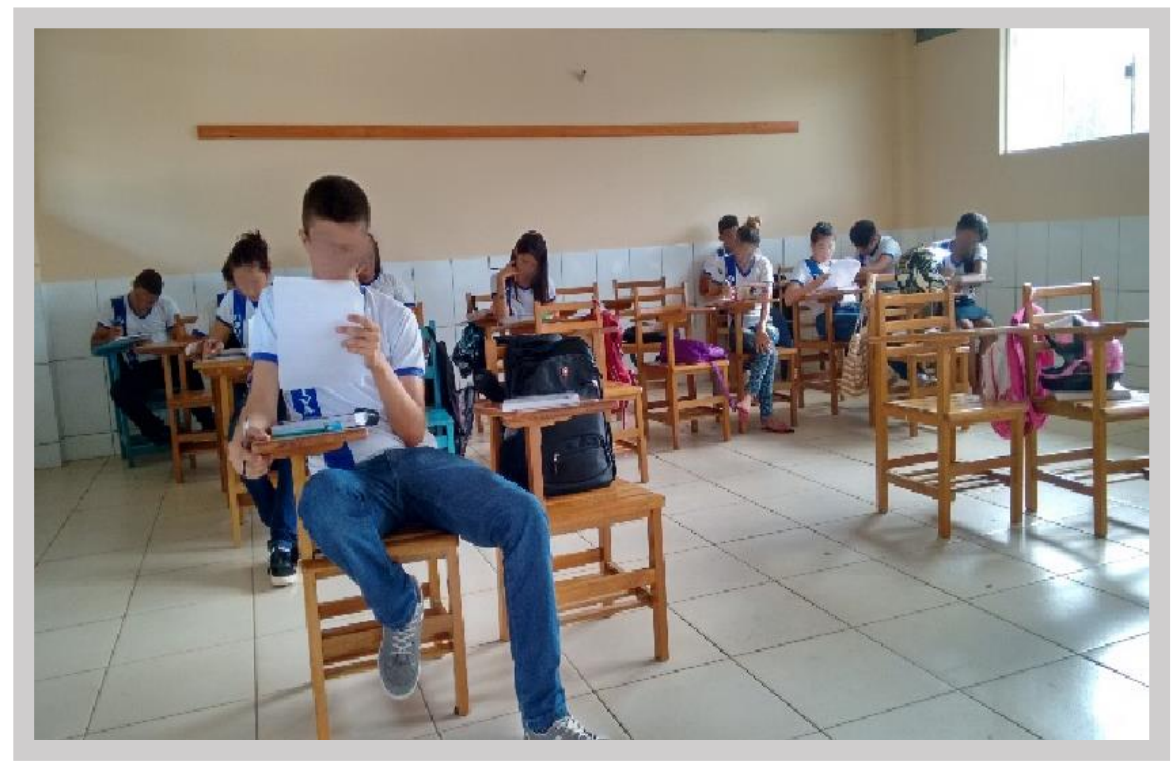

Figura 04: Aplicação do questionário com o objetivo de verificar a aprendizagem por parte dos estudantes.

Referente à questão de número 09 (nove), pretendia-se averiguar qual o entendimento e percepção dos alunos em relação à reação proveniente da adição de solução de $\mathrm{KMnO}_{4}$ com a mistura contendo óleo essencial e a mudança de coloração. Os alcenos quando sofrem oxidação branda por composto como o permanganato de potássio apresentam coloração castanho claro que identifica a sua presença no meio da reação, somente 12 (doze) alunos marcaram a alternativa certa, mais da metade dos alunos confundiram a diluição da solução de $\mathrm{KMnO}_{4}$ ocorrida quando foi vertida no tubo contendo apenas água, e assinalaram o resultado da coloração da reação como Lilás, neste caso consideramos um déficit de atenção por parte desses alunos os quais não analisaram a situação proposta e vivenciada na aula experimental.

A tabela 2 apresenta a análise por categoria de resposta da questão de número 10. Nesta, procurávamos saber a opinião do aluno de que maneira as experiências vivenciadas, a compreensão sobre produtos naturais, os óleos essenciais terpenos e como a hidrodestilação contribuíram para o seu aprendizado.

Tabela 02: Análise por categoria de respostas da questão 10.

\begin{tabular}{lc}
\hline \multicolumn{1}{c}{ Categoria de respostas } & Porcentagem \\
\hline Experimento contribuiu para melhoria do aprendizado & $13 \%$ \\
Processo de extração de óleos essenciais & $40 \%$ \\
Técnica de arraste a vapor para obtenção de óleos aromáticos em plantas & $27 \%$ \\
Óleos presentes em plantas para fabricação de remédios/perfumes & $80 \%$ \\
Não respondeu a questão & $20 \%$ \\
\hline
\end{tabular}

Vinte e dois alunos escreveram o máximo de cinco e o mínimo de duas linhas, esta quantidade de texto produzido é pequena em função do assunto abordado, porém, todos eles deixaram transparecer um aprendizado em relação às plantas medicinais e a importância das plantas aromáticas na obtenção de óleos essenciais. Para Sadoyama [37] essa dificuldade de responder perguntas discursivas resulta de problemas de compreensão dos textos propostos dificultando a produção textual, onde os conhecimentos prévios são imprescindíveis para compreendê-los, e atribuir significado a esse texto escrito enfatiza as necessidades de que escolas e universidades repensem a formação de seus alunos no que concerne à atividade da leitura. 


\section{CONCLUSÃO}

As leituras efetuadas por ocasião do levantamento bibliográfico tornaram possível a fundamentação teórica em autores que discorrem sobre o uso da experimentação através de aulas práticas na disciplina de Química e que serviram de base para a realização desta pesquisa. As dificuldades para desenvolver atividades experimentais que quase sempre são limitadas pela falta de um local apropriado nas Instituições de Ensino a nível Fundamental e Médio para sua realização, neste caso específico em virtude do laboratório encontrar em reforma, a experiência foi efetivada e adaptada à sala de aula.

Nos dias atuais o professor de Química necessita estar informado de todos os avanços, transformações e inovações tecnológicas voltadas para o ensino de Química que torne o aprendizado do aluno em nível significativo. Neste contexto, em aulas de práticas experimentais, nas quais os alunos manipulam objetos e ideias, permiti-lhe entender melhor os conceitos ou mesmo elaborá-los através do conhecimento proporcionado pela troca de experiências vivenciadas e desenvolvidas durante a aula.

A partir do estudo realizado percebemos as dificuldades dos alunos do Ensino Médio em compreenderem conceitos básicos de Química, pois, não conseguiram relacioná-los com a sua realidade, sendo um dos motivos porque não consegue estabelecer uma relação entre a teoria e a prática do professor em sala de aula. Quando o professor faz o uso de práticas experimentais utilizando como objeto de pesquisa a partir de elementos do conhecimento dos alunos, o sentido e significado ou o porquê da pesquisa ajudam no entendimento e socialização dos conhecimentos adquiridos na prática incentivando a uma aprendizagem significativa.

Diante do exposto, faz-se necessário a realização de estudos de metodologias que viabilizem atividades experimentais em sala aula. Esperamos que com a realização deste trabalho, ele possa contribuir como referência bibliográfica em futuros trabalhos, relacionada ao papel da experimentação pautada em elementos da realidade do aluno, e assim, contribuir com a qualidade do processo de ensino aprendizagem do estudo de Química.

\section{AGRADECIMENTOS}

A Diretoria da Escola Polivalente, Altamira - PA, pela oportunidade concedida. Ao Professor Erlon di Fran, a Universidade do Estado do Pará (UEPA) e em especial ao nosso Orientador Doutor Marcos Antônio Barros dos Santos.

\section{REFERÊNCIAS BIBLIOGRÁFICAS}

1. Silva LHA, Zanon LBA, experimentação no ensino de ciências. In: Schnetzler R. P. e Aragão R. M. R. (org.). Ensino de ciência: fundamentos e abordagens. Campinas: R. Vieira Gráfica e Editora, 2000. p. 120.

2. Amaral L. Trabalhos práticos de Química. São Paulo, 1996.

3. Chassot A. Alfabetização cientifica: Questões e desafios para a educação. Ed. UNIJUI, $5^{\text {a }}$ edição revisada, 2008.

4. Guimarães CC. Experimentação no ensino de química: caminhos e descaminhos rumo à aprendizagem significativa. Química Nova na Escola. 2009, 31(3):198-202.

5. Alves Filho JP. Regras da transposição didática aplicadas ao laboratório didático 1999. In: II Encontro nacional de pesquisa em educação em ciências (ENPEC); Valinhos SP: Anais.

6. Wolffenbüttel AN. Óleos Essenciais. [Internet] 2007 [Cited 2015 Set 02]. Disponível a partir de: http://www.oleoessencial.com.br/artigo_Adriana.pdf.

7. Queiroz SL. Do fazer ao compreender ciências: reflexões sobre o aprendizado de alunos de iniciação científica em Química. Ciência e Educação 2004, 10(1):41-53. Doi: dx.doi.org/10.1590/S151673132004000100003

8. Schnetzler RP. Pesquisa em Ensino de Química no Brasil. Conquistas e Perspectivas. 2002. Química Nova. v.25; p. 14-24.

9. Fonseca M.R.M. Completamente Química. Química geral. São Paulo: FTD, 2001. p. 624.

10. Russell J.B. Química Geral. 2. ed. São Paulo: LTC, 1994.

11. Demo P. É errando que a gente aprende. Escola a revista do professor. 2001 n. 144. São Paulo p. 49-51. 
12. Barberá O. Valdéz P. El trabajo Práctico en la Enseñanza de las Ciencias: Una Revisión. Enseñanza de las Ciencias 1996, 14(3):365-379.

13. Moraes R. Uma tempestade de luz: a compreensão possibilitada pela análise textual discursiva. Ciência e Educação 2003, 9(2):191-211.

14. Kovaliczn RA. O Professor de Ciências e de Biologia Frente às Parasitoses Comuns em Escolares. [Mestrado em Educação]. Ponta Grossa: Universidade Estadual de Ponta Grossa; 1999. 65p.

15. Galiazzi MC, Rocha JMB, Schmitz LC, Souza ML, Giesta S, Gonçalves FP. Objetivos das atividades experimentais no ensino médio: a pesquisa coletiva como modo de formação de professores de ciências. Ciência \& Educação 2001, 7(2):249-263.

16. BRASIL. Ciências da Natureza, Matemática e suas Tecnologias. Parâmetros Curriculares Nacionais Ensino Médio: Orientações Educacionais complementares aos parâmetros Curriculares Nacionais. Brasília: MEC/SEMTEC, 2002.

17. Ausubel DP, Novak JD, Hanesian H. Psicología educativa: un punto de vista cognoscitivo. México: Trillas, 1976.

18. Souza E.M. Seleção, comportamento fenotípico e genotípico e desenvolvimento de uma nova cultivar de manjericão (Ocimum Basilicum L.) para Sergipe. [Mestrado em Agro ecossistema] São Cristóvão: Universidade Federal de Sergipe; 2007. 79p.

19. Calixto JB. Biodiversidade como fonte de medicamentos. Ciência e Cultura 2003, 55:37-39.

20. Firmo WCA, Menezes VJM, Passos CEC. Contexto histórico, uso popular e concepção científica sobre plantas medicinais. Cad. Pesq. 2011 Dez; São Luís v. 18.

21. Maciel MAM. Plantas medicinais: a necessidade de estudos multidisciplinares. Química Nova. 2002, 25(3):429-438.

22. Accordi T, Santos MGKGS. Plantas Medicinais: levantamento etnobotânico em quintais e jardins na zona urbana da cidade de Altamira - Pará. [Monografia Curso de Licenciatura Plena em Ciências Naturais] Universidade do Estado do Pará; 2012. 72p.

23. Argenta SC, Argenta LC, Giacomelli SR, Cezarotto VS. Plantas medicinais: cultura popular versus ciência. Vivências. 2011 Mai;7(12): 51-60.

24. Santos GB, Gama PAF. Estudo Computacional das Propriedades Eletrônicas e Estruturais de Carotenoides. [Monografia Graduação em Licenciatura em Ciências Naturais]. Universidade do Estado do Pará, Altamira; 2013. 67p.

25. DI Stasi LC, Hiruma Lima CA. Plantas medicinais da Amazônia e na Mata Atlântica 2. ed. rev. e ampl. São Paulo: UNESP, 2002. 592 p.

26. Siddiqui BS. Two New Triterpenoids and a Steroidal Glycoside from the Aerial Parts of Ocimum Basilicum. Chem. Pharm. Bull 2007 Abr; 516-519.

27. Chechinel FV, Yunes RA. Química de Produtos Naturais - novos fármacos e a moderna farmacognosia. 2012 (Org.) 3.ed. Itajaí. UNIVALI.

28. Govindarajan M. Larvicidal and repellent properties of some essential oils against Culex tritaeniorhynchus Giles and Anopheles subpictus Grassi (Diptera: Culicidae). Experimental Parasitology. 2013,134:7-11.

29. Ausubel DP, Novak JD, Hanesian H. Psicologia Educacional. Rio Janeiro: Interamericana, 1980. 625p.

30. André MEDA. Estudo de Caso em Pesquisa e avaliação educacional. Liber Livro Editora. Brasília; 2005.

31. Yin RK. Estudo de caso: planejamento e métodos. 3. ed. Porto Alegre: Bookman, 2009.

32. Pina M, Saraiva MS, Souto NR. Aula expositiva dialogada baseada na pedagogia histórico-crítica. Artigo de Conclusão do Curso de Pós-Graduação [Metodologia do Ensino Superior] Universidade Federal de Rondônia. Porto Velho RO; 2004. 014 p.

33. Guimarães PIC, Oliveira REC, Abreu RG. Extraindo óleo essenciais de plantas. Química Nova na Escola. 2000 mai; $11: 1-3$.

34. Braathen PC. Aprendizagem mecânica e aprendizagem significativa no processo de ensino-aprendizagem de Química. Revista eixo 2012 Jan/ jun;1(1): 63-69.

35. Maldaner OA. A pesquisa como perspectiva de formação continuada do professor de química. Química. Nova 1999, 22(2):289-292.

36. Souza AP, Campos NMM, Vieira JDB, JR PCA. Vantagens das aulas práticas de laboratório utilizando produto regional. $9^{\circ}$ SIMPEQUI; Julho 2011.

37. Sadoyama G. Correlação de um teste de compreensão leitora com desempenho acadêmico práticas de leitura e produção textual no ensino superior. Anais do SIELP. Volume 2, Número 1. Uberlândia: EDUFU. 2012. 